\title{
Language teaching in the Engineering colleges of Chhattisgarh A perspective
}

\author{
By Dr. Jaya Mishra, \\ Humanities Department, RCET, CSVTU, Bhilai, India
}

\begin{abstract}
There are around sixty sundry technical colleges in Chhattisgarh where the students of the first year are compulsorily taught language and the subject is called 'Professional Communication in English'. The prime purpose is to help the students develop an optimum efficiency in their communication skills which may help them land good jobs in multinational companies. Having taught in standard English medium schools, initially I found this task as something very menial as the syllabus was totally devoid of any literary embellishments purely based on its basic language skills- the LSRW. But no sooner did I actually start teaching the subject than I realized my mistake. I had overestimated myself.If at schools, teaching English was a cake walk; at college level the path was strewn with stumbling blocks galore. The very simple reason- most of the students hailed from rural and underprivileged areas, no mean challenge for a language teacher.

They all come with one big dream in unison - of becoming a full-fledged engineer one day; of working at some coveted post in an MNC but, most of them find their dreams shattered at the very outset when they realize that they lack tremendously in effective communication skills. They soon come to know that in order to survive and succeed they need communicative competence in English Language. As an English teacher I found the task of grooming such students an absolutely evolving, challenging \& a rewarding experience. Through this paper I have reminisced on those experiences and have also shared those strategies which I consciously /unconsciously employed to help such students overcome their fears \& inhibitions related to language.
\end{abstract}

\section{Introduction}

One of the major effects of globalization in India has been the permeation of multinational companies which in turn has seen the burgeoning of private engineering colleges like mushrooms in almost every nook and cranny. In yonder years not everyone could fulfil the dreams of becoming an engineer because of the paucity of colleges but now this dream does not seem that farfetched. Every year thousands of students from different linguistic and cultural background seek admission into these colleges with the hope of becoming employable one day but, little do they realize that knowledge of a sizable amount of English becomes an essential imperative for this endeavour. 'Effective business communication is today an extremely desirable skill and a good communicator is often seen as an efficient corporate person'.

The present context is such that the need for English has become more manifold than it used to be. Today's engineer has to communicate with greater number of his counter parts across the globe. A large number of Indian engineers have to now travel to many continents and work away from their home country. In such conditions, 'An effective speaker can enhance his prestige and come to occupy more important positions in his organization. ${ }^{2 S S}$

The irony is that although English is the medium of instruction in most of the engineering colleges, language proficiency is not a criterion for selection in any such college. Therefore students hailing from rural and underprivileged areas or Hindi medium schools find this additional task of learning language quite cumbersome but they know that evasion could jeopardize their future. Hence some rush to join spoken English classes to overcome this problem but at the end of the day they feel cheated as they hardly make any progress or learn anything worthwhile in these classes. They do not have the insight to understand that language learning being a gradual and continuous process cannot be learnt overnight through crash courses.

\section{Discussion:}

2.1 Detrimental factors in language acquisition:

'Language is something we know and speak and write.'

As a language teacher our aim is to enable the students of engineering to write and speak English correctly and cohesively mainly for academic and professional purposes. But the cultural and linguistic diversity and the rural urban divide posts a great challenge both to the curriculum developers and practicing teachers and puts them on a life time test. For effective remedial teaching it becomes imperative to understand the nature of the learner's difficulties. ${ }^{4}$ Only when we know why an error has been committed can we start correcting it in a systematic way. 
Through constant observation, feedback and a healthy interaction with the students the following common problems were found out which they faced on a regular basis:

2.1.1Lack of conducive environment at home or school level: More than $60 \%$ students come from rural background where they are taught just the rudimentary nuances of language which is insufficient for them to acquire proficiency in language. Such students are not at par with the other more privileged students. This brings down their confidence level to a great extent.

The linguistic competence of even those who come from English medium schools is far from satisfactory, even though they have studied the language for 6-12 years. This is because in most of the Indian families or even English medium schools there is no culture of speaking or interacting in English.

Peter Strevens observes: "In some countries the fact of having followed a long course in English at school is no guarantee that a practical grasp of Common core of English has in fact been acquired, so that a Special purpose course in TTSE (Technical Technological and Scientific English) has to be preceded by an emergency course in English from scratch" ${ }^{5}$

2.1.2Influence of mother tongue: Thinking always takes place in one's mother tongue and this creates a major hurdle in acquiring spontaneity in a language which is not used on regular basis. Even translation from one's native language to some other language is possible only when one has become adept at new language. This was found to be one of the major problems of such students.

2.1.3Inadequate vocabulary: Lack of word power denudes a person from spontaneous and powerful expressions. In India most of the people read Hindi newspapers and magazines. Hence they are not able to develop rich vocabulary and expressions in English. This lacuna leaves the students often dumbfounded at many junctures.

2.1.4Apathetic attitude of the parents: Most of the parents lack awareness towards the importance of English language and they want their wards to focus more on the core subjects which would help them to crack competitive exams. This attitude reduces the interest in English language and consequently students start ignoring the subject totally.

2.1.5Psychological block: When such students are exposed to the college culture they feel timid and diffident in front of the students who are from better backgrounds/schools. Although they may have good percentage and sound knowledge of science subjects a mere snag becomes detrimental and is enough to lower their self esteem. Such students become inhibited and introverted and develop a psychological block while speaking. They anticipate ridicule and negative criticism from others and build a cocoon around themselves.

According to Allen and Widdowson, “...the difficulties which the students encounter arise not so much from a defective knowledge from the system of English, but from unfamiliarity with the English use.

2.1.6. Lack of practice: Spoken English needs practice which most of the students do not have. No language can be acquired in the absence of persistent practice.

2.1.7. Lack of self motivation and interest: Students do not take any initiative at their own level to improve their pathetic status. They just waste time in playing a blame game for their condition.

But who should take responsibility for this? The teachers; students; parents; or the society? According to a report only $1 / 3$ of the present pass out students is employable, remaining students are unemployable due to their poor knowledge of English.

\section{Strategies to combat these problems:}

The skill of communicating effectively is rarely an inherited gift. ${ }^{6}$ The majority of us, not blessed with instinctive flair, can nevertheless develop the ability. It is not easy, and it needs hard work. It depends partly on acquiring an understanding of technique, such as can be from books, classes, etc. It depends also on practical development of competence\& confidence either through on the job coaching by sensitive management or more often, off the job in the sort of seminar in which we can rapidly build compressed experience.

After finding out the primal problems responsible for language inefficiency, various learning strategies were devised with the cooperation and encouragement provided by the management but none were very successful. Our college is facilitated with communication lab but most of the times these periods are rendered ineffective as often they are replaced by others core subjects. Therefore we have no choice but to conduct the activities designed for the students either before or after college hours. But it worked against the psyche of the 
students who being tired by studying for eight long hours were not ready either mentally or physically to cope with something extra, even if it was vital for them.

Undeterred by these teething problems we decided to go on and worked out upon more effective strategies which were planned out for one semester comprising almost four months, catering to the level and needs of the students. Periods were accommodated by the management within the college hours and attending these classes was made mandatory.

The activities were divided into self and group modes which were an amalgam of all the basic skills of language, namely LSRW:

There is an assumption that a remedial program is re -teaching of grammar, but strictly register oriented and grammar based remedial course fail to motivate the learner. The students do not gain any

Confidence in the use of language: instead he is overawed by the amount of corrective learning he has to do. Very often he slips back to the same error that has been very painfully 'remedied'. The students are conscious of the error at the sentence level but when they write a continuous passage, they repeat the errors.

We decided to prepare tasks in which students have to bring out some comprehensible 'output' of language. The tasks were related to the language use that the engineer comes across in their profession. The learner has to reflect and produce language. The teacher has to interfere in the process when necessary. Correction has to be individualized.

\subsection{Self mode activities:}

To bring out the students from their initial state of lethargy and inertia we assigned them certain task sand saw to it that each and every student attempted it. In the beginning few among them resisted but finally they all had to succumb and the positive results motivated them to carry on with these self mode tasks .Here the students were asked to -

3.1.1 Read at least a piece of news/ article from English newspapers. After a couple of days they were made to write a précis or review on it.

3.1.2 Learn at least one word along with its antonym and expression every day and jot it down.(A regular and consistent practice of this helps them to learn at least thirty new words in a month )

3.1.3 To write (and speak) on any topic of their choice, where they could even describes a school/college event, or reminisce some incident, tell the qualities of their role model etc.

3.1.4 To speak as many words and sentences in English every day, at least during college hours.

Assigning the tasks was pretty simple but to see to it that they were practiced on a regular basis was more important for proper assessment.

For this, certain group mode activities were allocated to the students, where an entire class on the basis of its strength was divided into five to six groups. It was seen that each group had a balance of good and mediocre students.

\subsection{Group mode activities:}

3.2.1 In a group of eight, four pairs were made where each student was made to elicit information from his / her partner (about his school background, parents, hobbies aims etc) and after this each pair was called on the stage to introduce his partner to the entire class)

3.2.2 Quiz competition on vocabulary and grammar, (synonyms, antonyms, tenses, etc.) was conducted. Here, each group was made to design and conduct these competitions. The winner team was awarded.

3.2.3 Simple but interesting topics were given by one group to the other for intense group discussions, where they wore their thinking caps and participated with a lot of enthusiasm.

3.2.4 Group debates were conducted where two groups were made to counter each others' points.(Here one point is given to each contestant for cutting his opponent. Extra marks are added if all students participate in that group or deducted if somebody is reticent. This ensures active and complete participation from all the students which is our main endeavour.)

Richard Allright suggests capitalizing on the fact that collectively the students know the items and devise a minimal strategy course in which students are prompted to pool their collective knowledge and learn from each other. This will facilitate the development of learner independence from the teacher and mutual interdependence among the learners. ${ }^{8}$

3.2.5 Mock interviews were conducted where one group became the personnel and the other interviewees. (For this activity the interviewee group is made to write and pin up their resumes on the class notice board for perusal and framing of the questions by the interviewer group, a week prior.)

3.2.6 Each group is assigned to prepare and give presentations related to their core subjects. (Here marks are given by the other groups on the basis of content, voice modulation and body language.) 
3.2.7 Panel discussions were conducted from time to time to assess the general awareness ofthe students, where students from other groups were allowed to ask questions from the expert team.)

\section{Findings}

The above group activities made the students take the self mode activities seriously in order to outdo each other in group activities.

4.1 Through consistent participation in these activities the students were able to overcome their feelings of fear, shyness and inhibition related to language.

4.2 The students manifested genuine interest in all these activities because it provided a bit of relaxation and helped to distress them as they were able to vent out their frustrations related to anything or anybody.( for eg. education system, parental, peer or societal pressure etc.)

4.3 Without finding it cumbersome, around $60 \%$ of the students had started conversing in English by the end of the semester.

4.4 Most of the students who had tremendous stage fear had started looking out for opportunities for going on the stage.

4.5 The positive response from, and results of the students encouraged us teachers to go on with this endeavour. After all, it is the self assigned responsibility of a teacher to grow, and help others grow.

After all a journey of thousand miles begins with a single step...these and several such little steps made my journey of teaching English in the Engineering College a highly satisfying and fruitful activity.

\section{References}

[1] Chhabra T.N., Professional Communication, Sun India Publications, NewDelhi, 2009-2010pg1.3.

[2] Sharma R. C. \& Krishna Mohan, Business Correspondence and Report Writing, Tata McGraw Hills Publishing Company Ltd. New Delhi.2007.pg.236

[3] Sahu.N.S.Aspects of Linguistics, Prakash Book Depot, Bareilly, 1982.pg. 2

[4] Corder S.P. Introducing Applied Linguistics Middlesex: Penguin Education .1973

[5] Strevens, P “Technical Technological and Scientific English (TTSE)”. ELTJournal 27.3(1983):223-224

[6] Scott Bill. The Skills of Communicating. Jaico publishing House , Mumbai .2008.pg.4 